\title{
PENGARUH PENGETAHUAN KESELAMATAN DAN KESEHATAN KERJA TERHADAP PERILAKU PEKERJA KONSTRUKSI PADA PROYEK JALAN TOL NUSA DUA-NGURAH RAI-BENOA
}

\author{
Made Bayu Sambira Teja ${ }^{1}, \mathrm{I}$ N. Sutarja ${ }^{2}$, Gd. Astawa Diputra ${ }^{2}$
}

\begin{abstract}
Abstrak : Terdapat ketidaksesuaian antara pemahaman pengetahuan Keselamatan dan Kesehatan Kerja (K3) dengan penerapan perilaku pekerja konstruksi pada Proyek Pembangunan Jalan Tol Nusa Dua - Ngurah Rai - Benoa Paket 3, dimana proyek jalan tol ini dibangun di atas laut. Ada pekerja yang tidak sadar berperilaku tidak aman (unsafe action), ada pekerja yang bekerja dengan tidak aman meskipun sudah tahu bagaimana seharusnya bekerja secara aman, dan ada juga pekerja yang menyadari dirinya berkompeten, tetapi perlu pengarahan dan bimbingan. Untuk itu, perlu diketahui pengaruh pengetahuan K3 terhadap perilaku pekerja konstruksi dilihat dari beberapa aspek terkait K3 seperti definisi dan inisiasi, sistem manajemen, mekanisme alat pelindung diri, sarana dan prasarana, serta risiko K3. Teknik pengambilan sampel menggunakan Nonprobability Sampling dengan metode Sampling Insidental. Data penelitian diambil dari penilaian jawaban responden terhadap kuisioner oleh pekerja yang dijadikan sampel penelitian. Analisis korelasi digunakan untuk mengetahui hubungan antara pengetahuan K3 dengan perilaku pekerja. Analisis regresi digunakan untuk menjelaskan pengaruh aspek pengetahuan $\mathrm{K} 3$ terhadap perilaku pekerja konstruksi secara bersama-sama dengan analisis regresi linier berganda maupun parsial dengan analisis regresi linier sederhana. Hasil penelitian menunjukkan bahwa terdapat hubungan atau korelasi yang positif dan rendah antara pengetahuan K3 dengan perilaku pekerja. Dari aspek-aspek pengetahuan K3, maka aspek mekanisme penggunaan alat pelindung diri dan pemanfaatan sarana prasarana di tempat kerja berpengaruh secara positif/berbanding lurus dan tidak signifikan, sedangkan aspek pemahaman akan definisi dan inisiasi, pemahaman sistem manajemen $\mathrm{K} 3$ dan pemahaman akan risiko berpengaruh secara negatif/berbanding terbalik dan tidak signifikan terhadap penerapan pekerja konstruksi dalam berperilaku aman dan selamat.
\end{abstract}

Kata kunci : Pengetahuan K3, Perilaku Pekerja, Proyek Jalan Tol

\section{THE INFLUENCE OF OCCUPATIONAL HEALTH AND SAFETY KNOWLEDGE ON CONSTRUCTION WORKER BEHAVIOR IN NUSA DUA - NGURAH RAI - BENOA TOLL ROAD PROJECT}

\author{
Made Bayu Sambira Teja ${ }^{1}$, I Nyoman Sutarja ${ }^{2}$, dan Gede Astawa Diputra ${ }^{2}$
}

\begin{abstract}
There is incompatibility between the understanding of Occupational Health and Safety (OHS) knowledge with the application of construction workers behavior on the Nusa Dua Ngurah Rai - Benoa Toll Road Project Pack 3, where the toll road project was built above the sea. There are workers who work with unsafe although they already know how it should work safely, and there are also workers who found himself competent, but need direction and guidance. Therefore, need to know the influence of occupational health and safety knowledge on construction workers behavior seen from several aspects such as definitions and initiation, management systems, mechanisms of personal protective devices, facilities and infrastructure, as well as the risk of OHS. The sampling technique used Non probability sampling with Incidental Sampling method. Data were taken from the assessment of respondents' answers to the questionnaire by workers sampled in the research. Correlation analysis is used to determine the relationship between knowledge of OHS with worker behavior. Regression analysis was used to explain of the knowledge of OHS aspects influence on construction workers behavior together by using the multiple linear regression analysis and partial by using simple linear regression analysis. The research result showed that there is a positive correlation between knowledge of OHS with worker behavior. In term of the OHS knowledge aspects, the use of personal protective devices mechanism aspects and utilization of facilities and infrastructure at work site affect positively / directly proportional and not significant, while aspects understanding of the definition and initiation, understanding of the OHS management system and an understanding of the risks effect Negative / inversely and not significant on the application of construction workers behavior in a secure and safe.
\end{abstract}

Keywords : OHS Knowledge, Workers Behavior, Toll Road Project

\footnotetext{
${ }^{1}$ Mahasiswa Program Magister Teknik Sipil, Fakultas Teknik, Universitas Udayana, Denpasar

${ }^{2}$ Staf Pengajar Program Magister Teknik Sipil, Fakultas Teknik, Universitas Udayana, Denpasar
} 


\section{PENDAHULUAN}

Terkait dengan potensi risiko kecelakaan kerja pada pelaksanaan pekerjaan konstruksi, maka pengetahuan akan K3 pada suatu proyek konstruksi saat ini telah menjadi kebutuhan mendasar. Aspek K3 tidak akan bisa berjalan seperti seharusnya tanpa adanya intervensi dari manajemen berupa upaya terencana untuk mengelolanya (safety management), yang sering disebut dengan System Manajemen Keselamatan dan Kesehatan Kerja (SM K3). K3 konstruksi bukanlah sesuatu yang baru, mengingat ada beberapa regulasi terkait K3 sudah ada sejak Tahun 1970, seperti UU Nomor 1 Thn 1970 mengenai Keselamatan Kerja, dan beberapa tahun lalu Pemerintah juga menerbitkan Peraturan Menteri No. 9 Tahun 2008 tentang SMK3. Secara umum pengetahuan tentang K3 sangat luas, akan tetapi ada beberapa komponen K3 yang dipandang penting untuk dijadikan tolak ukur pemahaman K3. Komponen - kompenen tersebut adalah Definisi dan Inisiasi K3, Sistem Manajemen K3 (SMK3), Alat Pelindung Diri (APD), Sarana dan Prasarana K3, Risiko K3.

Dalam penulisan ini, penulis mengambil objek penelitian pada Proyek Jalan Tol Nusa Dua Ngurah Rai - Benoa Paket 3 dengan Penyedia Jasanya adalah Wika-Adhi-Hutama KSO dengan Lead Contractor PT. Hutama Karya Persero (Tbk). Cakupan pekerjaannya meliputi Main Road, Simpang Susun Ngurah Rai, Jalan Akses Ngurah Rai, dan Persimpangan Sebidang Jalan Ngurah Rai.

Pelaksanaan konstruksi proyek pembangunan jalan tol ini sebagian besar di atas laut dengan beberapa potensi hambatan yang dihadapi antara lain bekerja di ketinggian, pencahayaan saat bekerja malam hari, dipengaruhi kondisi pasang surut air laut, angin kencang yang tidak bisa diprediksi. Di samping itu, terdapat beberapa identifikasi bahaya dan risiko pada saat pelaksanaan pekerjaan seperti perahu terbalik, terkena alat kerja manual, jatuh dari ketinggian, tersengat listrik, tertimpa benda berat, terkena manuver alat, paparan debu tanah, kemacetan lalu lintas, jatuh ke air dalam, terjepit tiang pancang, suara keras di atas $86 \mathrm{db}$, terjepit bar cutter/bender, terimpa precast, dan sebagainya.

Oleh karena sudah teridentifikasi bahaya dan risiko pekerjaan pada proyek di atas laut ini, maka dari pihak penyedia jasa sudah seharusnya melakukan upaya manajemen yaitu adanya tindakan preventif, tanggap darurat dan mitigasi. Penerapan Safety Induction dan mekanisme penggunaan APD merupakan prioritas bagi keselamatan pekerja. Akan tetapi, pada pelaksanaan di lapangan, masih saja terdapat pekerja yang tidak mengikuti aturan yang sudah menjadi kebijakan mutu dan K3 perusahaan. Ada pekerja yang tidak sadar bahwa dia tidak kompeten dan mempunyai kebiasaan berperilaku tidak aman (unsafe action), ada pekerja yang tahu bagaimana melakukan pekerjaannya dengan aman dan selamat, tetapi tidak dilakukan, dan ada juga pekerja yang menyadari dirinya berkompeten, tetapi perlu pengarahan dan bimbingan dari orang lain. Secara umum terdapat ketimpangan antara pengetahuan tentang K3 dengan perilaku pekerja di tempat kerja.

Dari latar belakang permasalahan di atas, maka penelitian ini bertujuan untuk:

1. Untuk mengetahui pengaruh pengetahuan $\mathrm{K} 3$ terhadap perilaku pekerja konstruksi dilihat dari beberapa aspek terkait K3 seperti definisi dan inisiasi, sistem manajemen, mekanisme APD, sarana dan prasarana, serta risiko K3.

2. Untuk mengetahui pengaruh variabel-variabel pengetahuan K3 terhadap perilaku pekerja konstruksi secara bersama-sama.

3. Untuk mengetahui pengaruh variabel-variabel pengetahuan K3 terhadap perilaku pekerja konstruksi secara parsial.

\section{SISTEM MANAJEMEN K3 (SMK3)}

Berdasarkan Kepmenaker No. 5 Thn 1996, SMK3 merupakan salah satu komponen dari suatu system manajemen yang mencakup struktur organizasi, prencanaan, tanggungjawab, pelaksanaan, procedure, prosses, serta sumber daya yang diperlukan untuk pengembangan, aplikasi, capaian yang ditargetkan, kajian yang lebih mendalam, serta upaya untuk memelihara kebijakan $\mathrm{K} 3$ dalam pengendalian risiko terkait dengan pekerjaan sehingga terwujud suasana lingkungan kerja yang nyaman, efisiensi dan produktivitas yang optimal. Menurut OHSAS 18001:2007 SMK3: bagian dari system manajemen organizasi yang difungsikan untuk proses pengembangan dan menerapkan kebijakan K3 dan upaya pengendalian risiko $\mathrm{K} 3$.

1. System manajemen merupakan rangkaian unsure, dimana dalam usaha penetapan kebijakan dan tercapainya tujuan organizasi tersebut, memiliki keterkaitan satu dengan yang lain.

2. System manajemen mencakup struktur organizasi, kegiatan perencanaan (meliputi misalnya, penilaian risiko dan tujuan yang ingin dicapai), tanggungjawab, penerapan, prosedure, proses-proses terkait dan sumber daya.

Dalam siklus manajemen diggunakan prinsip atau konsep perencanaan (Plan), penerapan (Do), pemeriksaan (Check) dan tindakan perbaikan (Action). Sehingga, siklus manajemen akan berputar terus seiring kegiatan organizasi juga terus berjalan. 


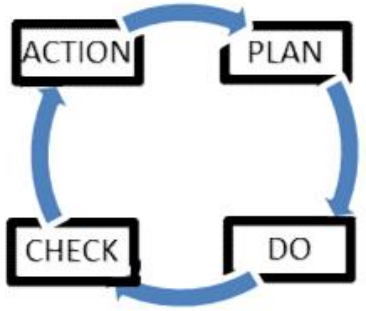

Gambar 1. Siklus Manajemen

\section{Alat Pelindung Diri (APD)}

Penggunaan APD merupakan keharusan dimana biasanya pekerja atau buruh bangunan yang bekerja di sebuah proyek atau pembangunan sebuah konstruksi bangunan, diwajibkan menggunakan APD tersebut. Hal ini sudah merupakan suatu kesepakatan oleh pemerintah melalui Departemen Tenaga Kerja Republik Indonesia. Adapun peralatan sudah semestinya sesuai dengan yang dipersyaratankan dan akan lebih baik jika bisa menunjang kenyamanan kerja serta memberikan proteksi yang handal dari risiko kecelakaan kerja.Beberapa jenis APD antara lain : masker, kacamata, sepatu pengaman, sarung tangan, topi pengaman (helmet), perlindungan telinga, perlindungan paru-paru, dan APD lainnya.

\section{Kesehatan Kerja}

$\mathrm{Hal}$ - hal yang terkait prihal kesehatan kerja diantaranya diatur dalam Undang-Udang Nomor 36 Thn 2009 mengenai Kesehatan. Prihal Kesehatan Kerja, dalam beberapa pasal menyebutkan tentang upaya kesehatan kerja yang bertujuan untuk memberikan perlindungan kepada tenaga kerja supaya membiasakan perilaku sehat dan terhindarkan dari bibit penyebab penyakit serta pengaruh negatif karena pekerjaan, meliputi pekerjaan di sektor informal dan formal, serta berpotensi terjadi juga kepada tiap-tiap pekerja dimanapun berada tidak hanya pekerja tertentu yang ada di wilayah area untuk beraktivitas para pekerja.

\section{Manajemen Proyek Konstruksi}

Definisi proyek adalah kumpulan kegiatan tertentu yang saling berhubungan erat satu dengan lainnya menuju sasaran yang diinginkan dimana proses atau kegiatan tersebut dilakukan selama kurun waktu yang ditentukan. Menurut $P M B O K$ Guide (2004), ada beberapa karakteristik penting yang dimiliki dalam sebuah proyek yaitu: temporary, unique, progressive elaboration. Manajemen proyek adalah perpaduan antara pengetahuan (knowledge), keahlian (skill), alat (tool) dan teknik (technique) pada kegiatan proyek konstruksi untuk mencapai tujuan sesuai kebutuhan pada proses konstruksi.

Berdasarkan jenis pekerjaannya, proyek diklasifikasikan sebagai berikut:

1. Proyek Konstruksi

2. Proyek Penelitian dan Pengembangan

3. Proyek yang Berhubungan dengan Manajemen Jasa

\section{Manajemen Risiko}

Definisi yang pertama adalah risiko merupakan peluang terjadinya kehilangan /kerugian, yang biasa digunakan untuk memperlihatkan kondisi yang menunjukkan adanya indikasi terjadi kerugian yang sangat mungkin bisa terjadi. Pengertian lainnya yaitu risiko merupakan kemungkinan kerugian, dimana kata kemungkinan bisa diartikan probabilitas sebuah kejadian yang ada diantara nol dan satu. Selanjutnya risk is uncertainty yaitu risiko adalah ketidakpastian baik yang bersifat subjektif maupun objektif. Ketidakpastian subjektif merupakan penilaian individu terhadap situasi risiko, sedangkan ketidakpastian objektif dimaksudkan sebagai frekuwensi relatif yang menggunakan perhitungan ilmiah sebagai dasar penilaian.

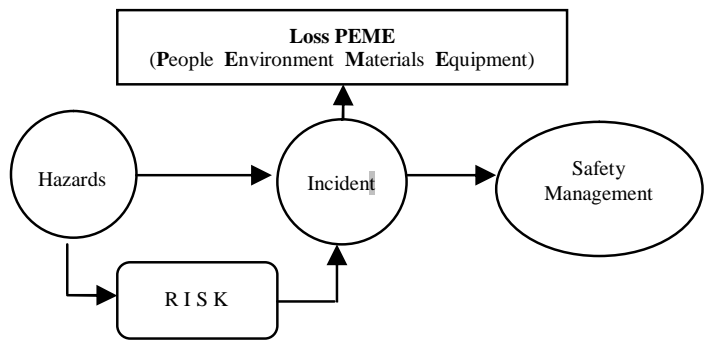

Gambar 2. Hubungan Bahaya dan Risiko

\section{Konsep Perilaku}

Perilaku secara umum menempatkan sasaran sebagai orientasi. Motivasi utama dari perilaku atau tindakan kita adalah adanya kehendak dalam usaha pencapaian suatu tujuan. Individu tersebut tidak selalu menyadari apa yang menjadi tujuan atau motivasi tersebut secara spesifik. Sebenarnya semua perilaku merupakan suatu seri aktivitas. Untuk mengubah budaya K3 bisa dilakukan dengan mengubah mindset (cara pandang) para pekerja. Disimpulkan bahwa 95\% kecelakaan kerja secara langsung berkaitan dengan perilaku tidak selamat sesaat sebelum kejadian kecelakaan kerja.

\section{Korelasi Pengetahuan K3 dengan Perilaku Pekerja Konstruksi}

Korelasi karakteristik pengetahuan K3 dengan perilaku pekerja pada di tempat kerja merupakan korelasi dua variable yang berkaitan dan mempengaruhi satu sama lain, sehingga korelasi antara dua variable tersebut bisa diketahui dimana dalam penelitian ini dikerjakan dengan Metode 
Analisis Regresi dengan bantuan Program SPSS dan Microsoft Excel.

\section{Uji Validitas, Reliabilitas dan Interpretasi Hasil Penelitian}

Sebagaimana diketahui di dalam suatu penelitian data memiliki peranan yang sangat penting, dikarenakan disamping sebagai gambaran variabel yang diteliti, dan dalam pembuktian hipotesis data juga berguna sebagai instrument utama. Oleh karena itu, sebuah instrument yang akan dipakai untuk membuktikan suatu hipotesis tersebut, seharusnya data yang dikumpulkan sebagai indikator dalam sebuah instrument, harus memiliki tingkat akurasi dan konsistensi yaitu Validitas dan Reliabilitas.

1. Validitas

$r$ hitung $=\frac{n\left(\sum X Y\right)-\left(\sum X\right)\left(\sum Y\right)}{\sqrt{\left[n \sum Z^{2}-\left(\sum X\right)^{2}\right) \cdot\left(n \sum Y^{2}-\left(\sum Y\right)^{2]}\right.}}$

Kaidah keputusan :

$t$ hitung $>t$ tabel berarti valid

$t$ hitung $<t$ tabel berarti tidak valid

\section{Reliabilitas}

Reliabilitas adalah menunjukkan pada tingkat kehandalan sesuatu yang dapat dipercaya dan dapat dihandalkan dengan menggunakan metode Alpha Cronbach's, rumus reliabilitas dengan metode Alpha adalah (Arikunto, 2002):

$r_{11}=\left[\frac{k}{k-1}\right]\left[1-\frac{\sum \sigma_{b}^{2}}{\sigma_{1}^{2}}\right]$

\section{Interpretasi Hasil Penelitian}

Penafsiran atas hasil penelitian terhadap hasil analisis data dilakukan untuk mendapatkan informasi lebih jauh yang berkaitan dengan hasil penelitian. Selain itu, interpretasi juga dimaksudkan untuk mendapatkan inferensi yang relevan dengan hasil penelitian.

\section{Analisis Regresi Linier}

Analisis Regresi merupakan suatu metode analisis untuk mengetahui keterkaitan atau hubungan antara beberapa variabel.

1. Analisis Regresi Linier Sederhana

Regresi linear sederhana merupakan bentuk paling sederhana dalam analisis regresi. Model matematis dari persamaan regresi linear sederhana adalah:

$\hat{\mathrm{y}}=\beta_{0}+\beta_{1} \mathrm{x}$

$\mathrm{y}=\beta_{0}+\beta_{1} \mathrm{x}+$

2. Analisis Regresi Linear Berganda

Pada pemodelan analisis regresi linear berganda mempunyai variabel prediktor minimal dua buah, yaitu $\mathrm{x}_{1}$ sampai dengan $\mathrm{x}_{\mathrm{k}}$. Model matematis dari persamaan regresi linear berganda adalah:

$\hat{\mathrm{y}}=\beta_{0}+\beta_{1} \mathrm{x}_{1}+\beta_{2} \mathrm{x}_{2}+\ldots \ldots+\beta_{\mathrm{k}} \mathrm{x}_{\mathrm{k}}$

$y=\beta_{0}+\beta_{1} x_{1}+\beta_{2} x_{2}+\ldots \ldots .+\beta_{k} x_{k}+\varepsilon \ldots$

\section{Metode Pengolahan Data}

Metode yang digunakan adalah Metode Suksesive Interval. Tahap awal yang dilakukan sebelum melakukan regresi berganda adalah dengan melakukan pengolahan data ordinal menjadi data interval dengan menggunakan Metode Suksesive Interval. Metode ini berguna untuk perubahan yang menghasilkan data interval yang berasal dari data ordinal. Data ordinal yang dihasilkan dari suatu daftar, seperti skala pengukuran yang menggunakan skala likert, yang tidak secara langsung menampilkan jawaban secara riil, dengan interval komparasi antara jawaban yang aktual akan terlihat kontras, oleh karena itu bisa dilanjutkan dengan mengolah data sehingga didapatkan jawaban atau penilaian respondent.

\section{METODE}

Dalam penelitian ini dipergunakan pendekatan penelitian kualitatif yaitu suatu metode mengumpulkan data yang sesuai dengan keadaan yang sebenarnya, serta menyajikan dan menganalisis sehingga bisa memberikan gambaran yang cukup jelas atas objek yang diteliti. Metode kualitatif bisa bermakna apabila data yang didapat lebih lengkap, lebih mendalam, dan kredibel sehingga tujuan penelitian tercapai. Metode ini tepat digunakan untuk meneliti status sekelompok manusia, perusahaan sebagai objek penelitian, yang bertujuan membuat deskriptif gambaran secara sistematis, factual dan akurat mengenai fakta-fakta serta hubungan antar fenomena yang diselidiki

\section{Lokasi Penelitian}

Penelitian ini berlokasi di Proyek Pembangunan Jalan Tol Nusa Dua - Ngurah Rai Benoa, khususnya Paket 3 yang terletak di Kabupaten Badung, Provinsi Bali.

\section{Penentuan Sumber Data}

Populasi pekerja pada proyek Pembangunan Jalan Tol Nusa Dua - Ngurah Rai - Benoa, Paket 3 adalah berjumlah 1159 orang. Pada penelitian ini, teknik pengambilan sampel dilakukan dengan metode Sampling Insidental. Teknik penyebaran kuisioner dengan cara meminta bantuan staf PT. Hutama Karya yang terlibat pada proyek Pembangunan Jalan tol Nusa Dua - Ngurah Rai Benoa Paket 3 untuk menyebarkan kuisioner, atau membagikan langsung pada pekerja konstruksi pada proyek tersebut yang siap bekerja sama dan dijadikan sumber data. Jumlah pekerja yang dijadikan sampel yaitu sebanyak 137 orang. 


\section{Jenis Data}

Untuk mendapatkan tujuan akhir dari penelitian, maka data yang diperlukan adalah data primer dan data sekunder.

\section{a. Data Primer}

Yaitu data yang diperoleh dari responden dengan mendistribusikan kuisioner dan atau wawancara langsung kepada beberapa pekerja konstruksi.

b. Data Sekunder

Data sekunder diperoleh dari Unit SMK3L PT. Hutama Karya seperti data umum proyek, RK3K Proyek, data jumlah pekerja, serta literatur-literatur dan media yang berhubungan dengan objek yang diteliti.

\section{Definisi Operasional Variabel}

Variabel bebas yaitu variabel yang mempengaruhi variabel lain atau variabel yang disebut variabel prediktor. Dalam penelitian ini sebagai variabel bebas adalah pengetahuan tentang $\mathrm{K} 3$ yang terdiri dari: Definisi atau Inisiasi K3 $\left(\mathrm{X}_{1}\right)$, Sistem Manajemen K3 $\left(\mathrm{X}_{2}\right)$, Mekanisme Alat Pelindung Diri $\left(\mathrm{X}_{3}\right)$, Sarana dan Prasarana K3 $\left(\mathrm{X}_{4}\right)$, Risiko K3 $\left(\mathrm{X}_{5}\right)$. Variabel tergantung yaitu variabel yang dipengaruhi oleh variabel bebas. Variabel tergantung dalam penelitian ini adalah Perilaku Pekerja Konstruksi (Y).

\section{Teknik Pengumpulan Data}

Pada penelitian ini, metode yang digunakan untuk mengumpulkan data adalah dengan cara sebagai berikut:

1. Pengumpulan Data Sekunder

Pengumpulan data sekunder dilakukan dengan cara dokumentasi dan pengumpulan data terkait $\mathrm{K} 3$ yang didapat baik dari penyedia jasa ataupun dari media yang berkaitan dengan objek penelitian.

2. Pengumpulan Data Primer

Data primer dikumpulkan dengan metode penyebaran kuisioner dimana responden akan diminta untuk menjawab pertanyaan, sehingga dapat memperoleh data pengaruh pengetahuan K3 terhadap perilaku pekerja konstruksi.

\section{Skala Pengukuran}

Semua variabel yang digunakan pada penelitian ini diukur dengan menggunakan Skala Likert. Dalam hal ini penulis berasumsi bahwa skala likert menghasilkan pengukuran variabel dalam Skala Interval. Ada lima alternatif pengukuran yang digunakan yaitu tipe Skala Likert dengan skor :

5 = Sangat Tahu

4 = Tahu

3 = Kurang Tahu

2 = Tidak Tahu

1 = Sangat Tidak Tahu

Uji Validitas dan Reliabilitas
Validitas sebuah alat ukur didasarkan pada criteria instrument terhadap fakta-fakta yang terjadi di lapangan, dimana validitas instrument tersebut harus memiliki ketepatan dan kecermatan untuk mendapatkan data yang valid. Cara yang digunakan untuk menguji validitas adalah dengan menggunakan program SPSS . Uji validitas dilakukan setiap butir soal. Item instrument dianggap valid jika $r$ hitung $>0,3$

Melakukan uji reliabilitas merujuk kepada konsistensi hasil pengukuran. Kalau hasilnya konsisten, maka instrument tersebut dapat dipercaya (reliable) atau dapat dihandalkan (dependable). Pengujian reliabilitas dapat menggunakan metode Alpha Cronbach. Koefisien dari Alpha Cronbach berkisar antara 0 sampai 1, untuk nilai kurang dari 0,6 secara umum instrument dianggap tidak reliable.

\section{Analisis Data}

Analisis data merupakan suatu proses pengolahan data yang diperoleh melalui survei. Analisis data yang dilakukan dalam penelitian ini adalah ;

\section{Statistik Deskriptif}

Statistik deskriptif adalah statistik yang digunakan untuk menggambarkan atau menganalisis suatu statistik hasil penelitian pengetahuan K3 sebagai objek yang diteliti.

\section{Analisis Regresi dan Korelasi}

Analisis regresi dan korelasi menggunakan program SPSS dan Microsoft Excel. Analisis regresi yang digunakan adalah Analisis Regresi Linear Berganda untuk mengetahui pengaruh aspek-aspek pengetahuan K3 secara bersama-sama terhadap perilaku pekerja konstruksi, kemudian Analisis Regresi Linear Sederhana untuk mengetahui pengaruh masing-masing aspek pengetahuan K3 secara parsial terhadap perilaku pekerja konstruksi

Analisis korelasi, untuk mengetahui korelasi pengetahuan K3 dengan perilaku pekerja konstruksi di tempat kerja dengan menggunakan analisis korelasi Pearson Product Moment (PPM).

\section{Cara Penyajian Data}

Cara penyajian data yang komunikatif akan dapat mudah untuk dipahami, sehingga diperlukan cara-cara tertentu untuk menyampaikan data tersebut, seperti penyajian data berupa tabel dan grafik. Di samping itu, hasil pengumpulan data juga bisa dibuat secara naratif, berupa deskripsi data yang diperoleh dari hasil pengolahan data. 


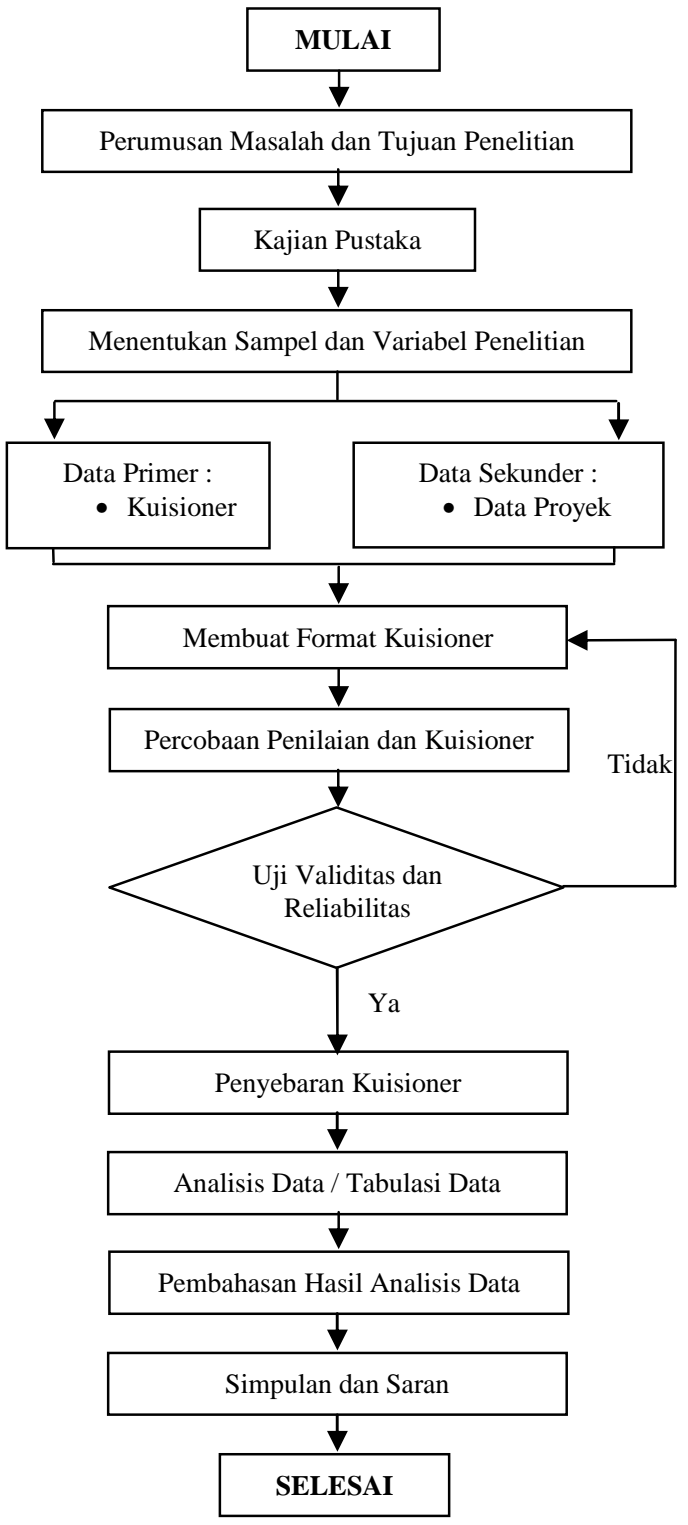

Gambar 3 Diagram Kerangka Analisis

\section{HASIL DAN PEMBAHASAN}

\section{Gambaran Umum Objek Penelitian}

Pembangunan jalan tol ini dilaksanakan dengan konsep Design and Built, yaitu pengguna jasa menyediakan basic design, kriteria desain dan penyedia jasa yang merencanakan simultan dengan pelaksanaan konstruksi. Pada minggu kedua Januari 2012 panitia pengadaan penyedia jasa pemborongan pembangunan jalan tol ini, telah berhasil melaksanakan tugasnya dan konsorsium telah menunjuk pemenang penyedia jasa sebagai berikut :

- Paket I sebagai lead contractor PT. Adhi Karya (Persero) Tbk.

- Paket II sebagai lead contractor PT. Waskita Karya (Persero).

- Paket III sebagai lead contractor PT. Hutama Karya (Persero).
- Paket IV sebagai lead contractor PT. Waskita Karya (Persero).

\section{Deskripsi Data}

1. Deskripsi Karakteristik Pekerja

a. Berdasarkan Umur

Tabel 1

Karakteristik Pekerja Berdasarkan Umur

\begin{tabular}{cccc}
\hline No & $\begin{array}{c}\text { Umur Pekerja } \\
\text { (Tahun) }\end{array}$ & $\begin{array}{c}\text { Jumlah } \\
(\text { Orang })\end{array}$ & $\begin{array}{c}\text { Persentase } \\
(\%)\end{array}$ \\
\hline 1. & $17-25$ & 18 & 13.139 \\
2. & $25-40$ & 61 & 44.526 \\
3. & $>40$ & 58 & 42.336 \\
& Jumlah & 137 & 100
\end{tabular}

Sumber: Tabulasi hasil survei

b. Berdasarkan Kontrak Kerja

Tabel 2

Karakteristik Pekerja Berdasarkan Kontrak Kerja

\begin{tabular}{cccc}
\hline No & $\begin{array}{c}\text { Sifat Kontrak } \\
\text { Kerja }\end{array}$ & $\begin{array}{c}\text { Jumlah } \\
\text { (Orang) }\end{array}$ & $\begin{array}{c}\text { Persentase } \\
(\%)\end{array}$ \\
\hline 1. & Kary. Tetap & 20 & 14.599 \\
2. & Kary. Lepas & 67 & 48.905 \\
3. & $\begin{array}{c}\text { Kary. Kontrak } \\
\text { Proyek }\end{array}$ & 50 & 36.496 \\
& Jumlah & 137 & 100 \\
\hline
\end{tabular}

Sumber: Tabulasi hasil survei

c. Berdasarkan Pendidikan

Tabel 3

Karakteristik Pekerja Berdasarkan Pendidikan

\begin{tabular}{cccc}
\hline No & $\begin{array}{c}\text { Tingkat } \\
\text { Pendidikan }\end{array}$ & $\begin{array}{c}\text { Jumlah } \\
\text { (Orang) }\end{array}$ & $\begin{array}{c}\text { Persentase } \\
(\%)\end{array}$ \\
\hline 1. & SMP & 41 & 29.927 \\
2. & SMA & 44 & 32.117 \\
3. & Sarjana & 52 & 37.956 \\
& Jumlah & 137 & 100 \\
\hline
\end{tabular}

Sumber: Tabulasi hasil survei

2. Deskripsi Jawaban Pekerja Berdasarkan Hasil Survei

Berdasarkan hasil survei dari pekerja (responden) pada Proyek Pembangunan Jalan Tol Nusa Dua - Ngurah Rai - Benoa Paket III yang dilakukan dengan menyebarkan kuisioner dan informed consent selama satu bulan. Dengan beberapa pertanyaan pada masing - masing variabel, yaitu Definisi dan Inisiasi K3 (Variabel $\mathrm{X}_{1}$ ), Sistem Manajemen K3 (Variabel $\mathrm{X}_{2}$ ), Alat Pelindung Diri (Variabel $\mathrm{X}_{3}$ ), Sarana dan Prasarana K3 (Variabel $\mathrm{X}_{4}$ ), Risiko K3 (Variabel $\mathrm{X}_{5}$ ).

Pengaruh Variabel Pengetahuan K3 terhadap Perilaku Pekerja Konstruksi Secara Bersama sama 
Metode perhitungan yang digunakan untuk mengetahui hasil perhitungan Pengaruh Pengetahuan K3 terhadap Perilaku Pekerja Konstruksi secara bersama - sama adalah metode Analisis Regresi Linier Berganda dengan bantuan program software Microsoft Excel. Adapun langkah - langkah dalam metode ini yaitu dengan menghitung nilai konstanta dan koefisien regresi, analisis varian, uji $-\mathrm{t}$, menentukan koefisien korelasi dan determinasi. Dari hasil perhitungan, maka model persamaan regresi yang didapat adalah sebagai berikut : $\mathrm{Y}=3.9717-1.3711 \mathrm{X}_{1}-$ $0,8311 \mathrm{X}_{2}+1.9594 \mathrm{X}_{3}+0.3572 \mathrm{X}_{4}-0.1049 \mathrm{X}_{5}$

1. Analysis of Varian (ANOVA)

Tabel 4

Analysis of Varian (ANOVA)

\begin{tabular}{lccccc}
\hline & $D f$ & $S S$ & $M S$ & $F$ & Sig F \\
\cline { 5 - 6 } Regression & 5 & 5.229 & 1.046 & 1.929 & 0.094 \\
Residual & 131 & 71.017 & 0.542 & & \\
Total & 136 & 76.246 & & & \\
\hline
\end{tabular}

Sumber : Data Analisis Regresi Excel

2. Uji-t

Tabel 5

Hasil Perhitungan Uji - t

\begin{tabular}{ccccccccc}
\hline Variabel & $\begin{array}{c}\text { Koef. } \\
(B)\end{array}$ & $S E$ & $T$ & $\begin{array}{c}t- \\
\text { tabel }\end{array}$ & $p(t)$ & \multicolumn{2}{c}{$C I 95 \%$} \\
Konst. & 3.972 & 0.465 & 8.548 & 1.978 & 0.000 & 3.053 & 4.891 \\
$X 1$ & -1.371 & 1.028 & 1.333 & 1.978 & 0.092 & -3.406 & 0.663 \\
$X 2$ & -0.831 & 0.482 & 1.723 & 1.978 & 0.044 & -1.785 & 0.123 \\
$X 3$ & 1.959 & 0.942 & 2.080 & 1.978 & 0.019 & 0.096 & 3.822 \\
$X 4$ & 0.357 & 0.566 & 0.631 & 1.978 & 0.265 & -0.763 & 1.478 \\
$X 5$ & -0.105 & 0.087 & 1.202 & 1.978 & 0.116 & -0.277 & 0.068 \\
\hline
\end{tabular}

Sumber : Data Analisis Regresi Excel

3. Menghitung Nilai Korelasi dan Determinasi

Dari hasil perhitungan, maka didapatkan nilai:

Koefisien Korelasi $(r)=0.262$, Koefisien Determinasi $(r$ square $)=0.068$, Penyesuaian Koefisien Determinasi (adjusted $r$ square $)=0.033$

\section{Pengaruh Masing-masing Variabel Pengetahuan K3 terhadap Perilaku Pekerja Konstruksi Secara Parsial}

Metode perhitungan yang digunakan untuk mengetahui hasil perhitungan pengaruh masing masing variabel Pengetahuan K3 terhadap Perilaku Pekerja Konstruksi secara parsial adalah metode Analisis Regresi Linier Sederhana dengan bantuan program software Microsoft Excel . Adapun langkah - langkah dalam metode ini yaitu dengan menghitung nilai konstanta dan koefisien regresi, analisis varian, uji $-\mathrm{t}$, menentukan koefisien korelasi dan determinasi.

1. Pengaruh Variabel Definisi dan Inisiasi K3 (X1) terhadap Perilaku Pekerja Konstruksi (Y)

a. Analysis of Varian (ANOVA)

Tabel 6

ANOVA Variabel Definisi dan Inisiasi

\begin{tabular}{ccccccc}
\hline $\begin{array}{c}\text { Sumber } \\
\text { Variasi }\end{array}$ & SS & Df & MS & F hit & Ftabel & P(f) \\
\hline Regresi & 0.240 & 1 & 0.240 & 0.426 & 3.911 & 0.515 \\
Error & 76.006 & 135 & 0.563 & & & \\
TOTAL & 76.246 & 136 & & & & \\
\hline
\end{tabular}

Sumber : Data Analisis Regresi Excel

b. $\mathrm{Uji}-\mathrm{t}$

Tabel 7

Uji - t Variabel Definisi dan Inisiasi

\begin{tabular}{lcccccccc}
\hline Var & $\mathrm{B}$ & $\mathrm{SE}$ & $\mathrm{T}$ & $\begin{array}{c}\mathrm{t} \\
\text { tabel }\end{array}$ & $\mathrm{P}(\mathrm{t})$ & \multicolumn{2}{c}{ CI 95\% } \\
& & & & & Lower & Upper \\
\hline Konst. & 3.723 & 0.306 & 12.168 & 0.000 & 3.118 & 4.329 & 3.723 \\
$\mathrm{X} 1$ & 0.072 & 0.110 & 0.653 & 0.515 & -0.145 & 0.288 & 0.072
\end{tabular}

Sumber : Data Analisis Regresi Excel

Dari tabel Uji-t didapatkan model persamaan regresinya yaitu: $\mathrm{Y}=3.723+0.072 \mathrm{X}_{1}$

c. Menghitung Nilai Korelasi dan Determinasi

Dari hasil perhitungan, maka didapatkan nilai: Koefisien Korelasi $(r)=0.056$, Koefisien Determinasi $(r$ square $)=-0.004$

2. Pengaruh Variabel Sistem Manajemen K3 $\left(\mathrm{X}_{2}\right)$ terhadap Perilaku Pekerja Konstruksi (Y)

Dari tabel Uji-t didapatkan model persamaan regresinya yaitu: $\mathrm{Y}=3.829+0.033 \mathrm{X}_{2}$, Koefisien Korelasi $(r)=0.028$, Koefisien Determinasi $(r$ square $)=0.001$

3. Pengaruh Variabel Alat Pelindung Diri $\left(X_{3}\right)$ terhadap Perilaku Pekerja Konstruksi (Y)

Dari tabel Uji-t didapatkan model persamaan regresinya yaitu: $\mathrm{Y}=3.653+0.097 \mathrm{X}_{3}$, Koefisien Korelasi $(r)=0.077$, Koefisien Determinasi $(r$ square $)=0.006$

4. Pengaruh Variabel Sarana dan Prasarana K3 $\left(\mathrm{X}_{4}\right)$ terhadap Perilaku Pekerja Konstruksi (Y)

Dari tabel Uji-t didapatkan model persamaan regresinya yaitu: $\mathrm{Y}=3.678+0,087 \mathrm{X}_{4}$, Koefisien Korelasi $(r)=0.067$, Koefisien Determinasi $(r$ square $)=0.004$

5. Pengaruh Variabel Risiko K3 $\left(\mathrm{X}_{5}\right)$ terhadap Perilaku Pekerja Konstruksi (Y). 
Dari tabel Uji-t didapatkan model persamaan regresinya yaitu: $\mathrm{Y}=4.309-0,098 \mathrm{X}_{5}$, Koefisien Korelasi $(r)=0.095$, Koefisien Determinasi $(r$ square $)=0.009$

\section{HASIL DAN PEMBAHASAN} Uji Validitas dan Reliabilitas

Sebelum dilakukan penyebaran kuisioner kepada responden, terlebih dahulu dilakukan uji validitas dan reliabilitas instrument penelitian. Oleh karena keterbatasan waktu, pada penelitian ini uji validitas dan reliabilitas digunakan sepuluh responden.

1. Uji Validitas

Uji Validitas digunakan untuk mengetahui ketepatan kuisioner untuk mendapatkan data yang tepat. Analisis yang digunakan adalah analisis korelasi product moment yaitu korelasi antara item pertanyaan terhadap totalnya. Berdasarkan hasil analisis dengan program SPSS (Lampiran) didapat nilai korelasi > r tabel $(0,632)$

2. Uji Reliabilitas

Suatu instrument dikatakan reliable jika memiliki konsistensi dan handal bila dilakukan berulang kali terhadap gejala yang sama. Berdasarkan hasil analisis dengan program SPSS (Lampiran) didapat nilai korelasi > $r$ tabel $(0,632)$

Uji Faktor - faktor yang Mempengaruhi Perilaku Pekerja

1. Uji Autokorelasi

Tabel 8. Nilai Korelasi dan Determinasi

\begin{tabular}{lc}
\hline \multicolumn{2}{c}{ Regression Statistics } \\
\hline Multiple R & 0.262 \\
R Square & 0.068 \\
Adjusted R Square & 0.033 \\
Standard Error & 0.736 \\
Observations & 137 \\
\hline
\end{tabular}

Sumber : Data Analisis Regresi Excel

Berdasarkan Tabel 8 bahwa terdapat korelasi atau hubungan antara Pengetahuan K3 dengan Perilaku Pekerja yaitu sebesar 0,262 (>0). Sedangkan pengaruh variabel dependent terhadap variabel independent, ditunjukkan dengan nilai koefisien determinasi yang sudah disesuaikan yaitu sebesar 0,033 (3,3\%). Hal ini menunjukkan bahwa hanya $3,3 \%$ sumbangan pengaruh yang diberikan faktor - faktor pengetahuan K3 terhadap perilaku pekerja.

2. Pengaruh Variabel Pengetahuan K3 secara bersama - sama terhadap Variabel Perilaku Pekerja

Dari Tabel 8 dapat diketahui bahwa 3,30\% keragaman yang terjadi pada variabel Perilaku Pekerja dapat diduga dari kombinasi variabel Definisi dan Inisiasi, Sistem Manajemen, Alat Pelindung Diri, Sarana Prasarana, dan Risiko.
Sedangkan sisanya dijelaskan atau dipengaruhi variabel lainnya.

Kombinasi variabel Definisi dan Inisiasi, Sistem Manajemen, Alat Pelindung Diri, Sarana Prasarana, dan Risiko tidak signifikan untuk menduga variabel Perilaku Pekerja, hal ini ditunjukkan dengan nilai $\mathrm{F}$ hitung $(1,929)$ lebih kecil dari f tabel $(2,283)$.

3. Pengaruh masing - masing Variabel Pengetahuan K3 secara parsial terhadap Variabel Perilaku Pekerja

Metode perhitungan yang digunakan untuk mengetahui hasil perhitungan pengaruh masing masing variabel Pengetahuan K3 terhadap Perilaku Pekerja Konstruksi secara parsial adalah metode Analisis Regresi Linier Sederhana dengan bantuan program software Microsoft Excel.

Adapun langkah - langkah dalam metode ini yaitu dengan menghitung nilai konstanta dan koefisien regresi, analisis varian, uji - $t$, menentukan koefisien korelasi dan determinasi.

1. Regresi Linear Sederhana pada Variabel Definisi dan Inisiasi K3

Dari perhitungan ANOVA diketahui bahwa nilai f hitung $(0,426)<\mathrm{f}$ tabel $(3,911)$ dan signifikasi $p(f) 0,515>\alpha(0,05)$. Hal ini berarti pengaruh variabel Definisi dan Inisiasi tidak signifikan terhadap variabel Perilaku Pekerja.

2. Regresi Linear Sederhana pada Variabel Sistem Manajemen K3

Dari perhitungan ANOVA diketahui bahwa nilai f hitung $(0,105)<\mathrm{f}$ tabel $(3,911)$ dan signifikasi $p(f) 0,746>\alpha(0,05)$. Hal ini berarti pengaruh variabel Sistem Manajemen tidak signifikan terhadap variabel Perilaku Pekerja.

3. Regresi Linear Sederhana pada Variabel Alat Pelindung Diri

Dari perhitungan ANOVA diketahui bahwa nilai f hitung $(0,808)<\mathrm{f}$ tabel $(3,911)$ dan signifikasi $p(f) 0,370>\alpha(0,05)$. Hal ini berarti pengaruh variabel Alat Pelindung Diri tidak signifikan terhadap variabel Perilaku Pekerja.

4. Regresi Linear Sederhana pada Variabel Sarana dan Prasarana K3

Dari perhitungan ANOVA diketahui bahwa nilai f hitung $(0,610)<\mathrm{f}$ tabel $(3,911)$ dan signifikasi $p(f) 0,436>\alpha(0,05)$. Hal ini berarti pengaruh variabel Sarana dan Prasarana tidak signifikan terhadap variabel Perilaku Pekerja.

5. Regresi Linear Sederhana pada Variabel Risiko K3. Dari perhitungan ANOVA diketahui bahwa nilai $\mathrm{f}$ hitung $(1,223)<\mathrm{f}$ tabel $(3,911)$ dan signifikasi $\mathrm{p}(\mathrm{f}) 0,271<\alpha$ $(0,05)$. Hal ini berarti pengaruh variabel Risiko tidak signifikan terhadap variabel Perilaku Pekerja. 


\section{SIMPULAN DAN SARAN}

\section{Simpulan}

1. Didapatkan nilai Koefisien Korelasi ( $r$ ) sebesar 0,262 dan berdasarkan interpretasi koefisien nilai korelasi berada diantara 0,200 - 0,399, artinya terdapat hubungan atau tingkat korelasi yang rendah antara Pengetahuan K3 dengan Perilaku Pekerja. Sedangkan nilai Koefisien Determinasi (adjusted $r$ square) sebesar 0,033 yang artinya hanya sebesar 3,3\% dari aspek aspek Pengetahuan K3 yang berpengaruh terhadap Perilaku Pekerja Konstruksi dan sisanya sebesar $96,7 \%$ dipengaruhi oleh variabel lain.

2. Tidak ada pengaruh secara signifikan dari variabel - variabel pengetahuan K3 (Definisi dan Inisiasi, Sistem Manajemen, Alat Pelindung Diri, Sarana dan Prasarana, Risiko) secara bersama-sama terhadap Perilaku Pekerja Konstruksi pada Proyek Pembangunan Jalan Tol Nusa Dua - Ngurah Rai - Benoa, Paket 3. Hal ini ditunjukkan berdasarkan hasil perhitungan Uji - $\mathrm{t}$ dengan menggunakan metode perhitungan Regresi Linier Berganda nilai $t$ hitung < nilai $t$ tabel $(1,978)$

3. Tidak ada pengaruh secara signifikan dari variabel - variabel pengetahuan K3 (Definisi dan Inisiasi, Sistem Manajemen, Alat Pelindung Diri, Sarana dan Prasarana, Risiko) secara parsial terhadap Perilaku Pekerja Konstruksi pada Proyek Pembangunan Jalan Tol Nusa Dua - Ngurah Rai - Benoa,Paket 3. Hal ini ditunjukkan berdasarkan hasil perhitungan Uji - $\mathrm{t}$ dengan menggunakan metode perhitungan Regresi Linier Sederhana dari masing - masing variabel Pengetahuan K3 terhadap variabel Perilaku Pekerja Konstruksi yaitu nilai $t$ hitung < nilai $t$ tabel $(1,978)$

\section{Saran}

1. Perlu diadakan pelatihan, pembinaan dan informasi yang lebih intensif mengenai K3 oleh pihak berwenang kepada seluruh pekerja yang terlibat pada Proyek Pembangunan Jalan Tol Nusa Dua-Ngurah Rai- Benoa Paket 3, sehingga pekerja konstruksi bisa lebih memahami dan mendalami Pengetahuan K3, baik secara konsep maupun dalam penerapan berperilaku.

2. Dicoba juga penelitian dilakukan dengan menggunakan aspek-aspek (variabel) lainnya yang mungkin berpengaruh terhadap perilaku pekerja, seperti

a. Adanya jaminan kesehatan terhadap pekerja, b. Adanya konsekuensi secara tegas terhadap pelanggar aturan,

c. Situasi kondisi lingkungan kerja,

d. Cara berkomunikasi atau berkoordinasi antara atasan kepada bawahan,

e. Adanya faktor socio culture yang kuat,

f. Peningkatan potensi diri, dan lain sebagainya.

\section{DAFTAR PUSTAKA}

Anizar. 2009. Teknik Keselamatan Dan Kesehatan Kerja Di Industri. Yogyakarta: Graha Ilmu.

Anonim. 2004. Undang-Undang Ketenagakerjaan Lengkap . Jakarta: Sinar Grafika.

Anonim. 2010. Undang-Undang Kesehatan Dan Rumah Sakit 2009 . Yogyakarta: Pustaka Yustisia.

Anonim. 2013. Himpunan Peraturan Perundang Undangan Perlindungan Dan Pengelolaan Lingkungan Hidup. Bandung: Fokus Media.

Anonim. 2013. Media Tren Konstruksi (Inspirasi Bagi Profesional). Tangerang: Adil Maju Bersama.

Darmawi, H. 1990. Manajemen Risiko . Jakarta : Bumi Aksara.

Nawari. 2010. Analisis Regresi Dengan MS Excel 2007 Dan SPSS 17. Jakarta: Gramedia.

Notoatmodjo, S. 1993. Pengantar Pendidikan Kesehatan dan Ilmu Perilaku Kesehatan. Yogyakarta: Andi Offset.

Notoatmodjo, S. 2003. Pendidikan dan Perilaku Kesehatan. Jakarta: PT. Rineka Cipta.

Notoatmodjo, S. 2007. Promosi Kesehatan dan Ilmu Perilaku. Jakarta: PT. Rineka Cipta.

Santosa, B. 2009. Manajemen Proyek Konsep \& Implementasi. Yogyakarta: Graha Ilmu.

Somad, I 2013 Teknik Efektif Dalam Membudayakan Keselamatan \& Kesehatan Kerja. Jakarta: Dian Rakyat.

Soehatman, R. 2010. Sistem Manajemen Keselamatan Dan Kesehatan Kerja OHSAS 18001. Jakarta : Dian Rakyat

Sugiyono. 2008. Metode Penelitian Kuantitatif, Kualitatif, R \& G. Bandung: Alfabeta.

Tresnaningsih, E. 2007. Kesehatan dan Keselamatan Kerja Laboratorium Kesehatan. Jakarta: Pusat Kesehatan Kerja.

Winardi, J. 2004. Manajemen Perilaku Organisasi. Jakarta: Kencana Prenada Media.

Wulfram I. E. 2012. Selamatkan Bumi Melalui Konstruksi Hijau. Yogyakarta: Andi Offset. 